\title{
The Analysis of Doosan S500-LCV Excavator Maintenance Planning to Reduce Downtime Using Reliability Centered Maintenance (RCM) Method
}

\author{
Sidiq Auda ${ }^{1}$ and Suparno ${ }^{1}$
}

\begin{abstract}
PT $X$ is a company engaged in construction field and heavy machinery services. PT $X$ uses excavators as a tool to mine rock sand. In 2018, the company has planned to increase production capacity. The increase of production capacity will be directly related to the operational capability of the unit which must always be maintained. The problem in this study is the occurrence of unit downtime that cannot be predicted and occurs in a relatively long time. The components damage of the excavator causes the unit to be unable to operate to increase production. The maintenance of the Doosan S500-LCV excavator at PT $X$ is currently not optimal because the downtime that occurs in the unit is still relatively high. Standard maintenance procedure of excavator units need to be evaluated in order to minimize the occurrence of downtime so that the unit can be used for maximum production. The method used in this analysis is the Reliability Centered Maintenance (RCM) method with evaluating maintenance carried out and giving the right maintenance suggestion. From the results of the analysis and discussion, the critical components of the S500-LCV excavator in PT X are Bucket, Control Valve, Radiator, Alternator and Hydraulic Breaker. Proposed maintenance based on the RCM method and the consideration of S500-LCV maintenance costs at $P T X$ are bucket with preventive maintenance, control valve with a combination of preventive and corrective maintenance, radiator with preventive maintenance, alternator with a combination of preventive and corrective maintenance and hydraulic breakers with preventive maintenance.
\end{abstract}

Keywords-Downtime, Excavator, Maintenance, RCM.

\section{INTRODUCTION}

Excavators are one of heavy machinery that is often used by humans to carry out excavation of soil, sand and stone material. The purpose of using excavators is to help doing difficult work in order to be easier and lighter and able to accelerate the processing time [1]. In its operation, excavators are very costly enough to be used as optimally as possible. One important point to be able to optimize the costs that related with the operation of excavators is regarding the maintenance of these excavators. By carrying out proper maintenance, the ability of the unit to operate can be maximized so that the production result can increase. Now the damage has not been predicted so that

\footnotetext{
${ }^{1}$ Sidiq Auda and Suparno are with Departement of Technology Management, Institut Technologi Sepuluh Nopember, 60111, Indonesia. E-mail: auda.wbs@gmail.com; suparno@ie.its.ac.id.
}

the operational planning of the excavator unit cannot reach the target. This problem become the basis for the research that will be carried out. Maintenance excavator planning is carried out to minimize breakdown time. The research carried out was devoted to the 50 ton excavator brand of Doosan with the S500-LCV model.

The method used in this study is Reliability Centered Maintenance (RCM) analysis. Reliability Centered Maintenance (RCM) is a tool that is used to analyze the identification of failure management strategies proactively so that the right solution is obtained in maintaining a component or equipment. Evaluation using the RCM worksheet outlines some information, consequences and determination of the improvements that must be made.

Researchers conducted research on the analysis of appropriate maintenance for the Doosan S500-LCV excavator unit. The occurrence of downtime exceeding the allowable limit is a major problem in a company that is being carried out by research. Hopefully, this research will be able to provide an appropriate maintenance proposal for the company so that it can reduce the occurrence of downtime on the excavator unit. As we know that nowadays the maintenance of the S500-LCV excavator unit at PT $\mathrm{X}$ is less than optimal so that premature failure and breakdown time are high. So in the future, there will be basic data to determine the planning of S500-LCV excavator maintenance for rock sand mining at PT X.

\section{LITERATURE REVIEW}

\section{A. Excavator}

Excavators are heavy machinery from a group of shovels that are made to help excavating material below the ground surface such as trenches, holes for basements, road works, etc.[2]. According to [1], excavators or often called backhoe have three main components, namely:

a. The top of the revolving unit (can rotate), this section includes the operator cabin area, counter weight and engine area.

b. The bottom of the travel unit (for walking), this part can be called the excavator foot section.

c. Part attachment, this part is also often called by hand from the excavator

In its operation excavators operate by carrying out 4 main movements, namely the process of filling the bucket, 
swinging with the load, unloading the load, swinging back blankly. The four movements will determine the cycle time of the excavator.

\section{B. Maintenance}

The definition of maintenance according to Geraerds is all activities aimed at maintaining an item or tool and returning it to a physical state that can be considered to fulfill the function of the tool. The longer equipment used for a job then the ability to function will also decrease. Therefore, maintenance is needed so that the function of the tool can be close to a predetermined standard. [3], explains that maintenance consists of every action or activity (other than routine service during operations such as refueling or small adjustments) that changes the product or system to keep it in operational conditions or returns it to operational conditions if it fails.

There are two types of maintenance measures, namely preventive maintenance and corrective maintenance [3] :

a. Preventive maintenance, is a maintenance by analyzing and preventing the possibility of damage.

b. Corrective maintenance, is maintenance to restore the function of the equipment or system that has been damaged in its operational conditions.

\section{Downtime}

The definition of downtime is the total time from the start of damage to the component or system until it starts to be able to operate again or can be used as its function [4]. Downtime can be divided into two categories:

a. Active repair time, the length of downtime occurs because it takes a long time to repair damage. This is related to the environment, the level of technician skills, repair procedures, etc.

b. Administrative time, the length of downtime is affected by the administrative process in the form of administrative, filing, storage, etc.

\section{Pareto}

Vilfredo Pareto explained and found that $80 \%$ of land, property and wealth in Italy was owned by only $20 \%$ of the population. If we applied this discovery to human daily life, it is also very applicable in every condition and activity. This discovery is now better known as Pareto 80/20. After the discovery of Vilvredo Pareto about the 80/20 Pareto theory, a theorist named Juran conducted further research on the discovery. Juran used the basis of the Pareto discovery to bring in a principle called the Pareto Principle. This principle then explained that an $80 / 20$ percentage by Pareto is not absolute, but its core is actually in accordance with the pareto law proposed by Vilfredo Pareto. Juran explained that the percentage that occurs may be $85-15,90-10,95-5$ and so on. The core of
Pareto's Law and the Pareto Principle is that there 's a group of vital small object that bring effect. This objects must be sought for every problem so that the solutions can be appropriate.

\section{E. Reliability Centered Maintenance (RCM)}

Reliability Centered Maintenance (RCM) is a structured process used to identify failure management strategies and develop maintenance proactively for an asset and can also be used to find a number of better solutions in terms of maintenance so that assets or components can perform their functions [5]. RCM is essentially a tool for doing fail management. From the failure potential, an analysis is carried out through RCM. From the management of failure, it will conclude how the maintenance should be done for a system or component to operate according to its function.

According to [3], by implementing the RCM method we will get several benefits, including:

a. Reducing maintenance costs dirctly by minimizing corrective maintenance and performing preventive maintenance effectively.

b. Availability of processes and efficiency improvements by reducing production losses caused by failure of components or systems.

c. Optimization of resources and organizations by promoting good collaboration between sections and providing quality training for RCM members.

\section{F. Previous research}

Research on the maintenance analysis has been carried out by several previous researchers with different methods as well. The result of implementing previous research will be a comparison and reference in conducting this research. Summary of the research that has been done along with the research methods that related to the topic of maintenance can be seen on Table 1 .

\section{METHOD}

This research was conducted in several steps. The first step is identifying problems by conducting field studies (come to the location directly to get the facts) and conducting literature studies, then formulating existing problems and objectives of the problem. The second step is collecting data. Third step is processing the data and analyzing the data. Third step included data collection for excavator downtime, data of the function of excavator components, determining critical components using Pareto analysis through the minitab software 16 . The data of critical components that have been determined are then collected related to the maintenance costs and loss production costs. 
The $1^{\text {st }}$ International Conference on Business and Management of Technology (IConBMT)

August 3rd 2019, Institut Teknologi Sepuluh Nopember, Surabaya, Indonesia

TABLE 1.

SUMMARY PREVIOUS RESEARCH

\begin{tabular}{ccclll}
\hline \hline No & Year & Author & & \multicolumn{1}{c}{ Title } & \multicolumn{1}{c}{ Method } \\
\hline 1 & 2016 & $\begin{array}{c}\text { Vishnu, C. } \\
\text { R }\end{array}$ & Reliability Based Maintenance Strategy Selection in Process Plants: A Case Study & $\begin{array}{l}\text { Reliability Centered Maintenance } \\
\text { (RCM) }\end{array}$ \\
2 & 2016 & $\begin{array}{c}\text { Effendi, F. } \\
\text { A. }\end{array}$ & $\begin{array}{l}\text { Maintenance Policy Planning Analysis to Reduce Downtime with Reliability } \\
\text { Centered Maintenance II Method (case study at PT. X) }\end{array}$ & $\begin{array}{l}\text { Reliability Centered Maintenance } \\
\text { II (RCM II) }\end{array}$ \\
3 & 2017 & Denur & $\begin{array}{l}\text { Implementation of Reliability Centered Maintenance (RCM) on Ripple Mill } \\
\text { Machine }\end{array}$ & $\begin{array}{l}\text { Reliability Centered Maintenance } \\
\text { (RCM) }\end{array}$ \\
& \multirow{2}{*}{2018} & Verhagen, & $\begin{array}{l}\text { Predictive Maintenance for Aircraft Components using Proportional Hazard } \\
\text { W. J. C. }\end{array}$ & $\begin{array}{l}\text { Models } \\
\text { Proportional Hazard Models } \\
\text { (PHMs) }\end{array}$ \\
& \multirow{2}{*}{2018} & Gupta, G. & $\begin{array}{l}\text { Identification of Critical Components using ANP for Implementation of Reliability } \\
\text { Centered Maintenance }\end{array}$ & Analityc Network Process (ANP) \\
\hline \hline
\end{tabular}
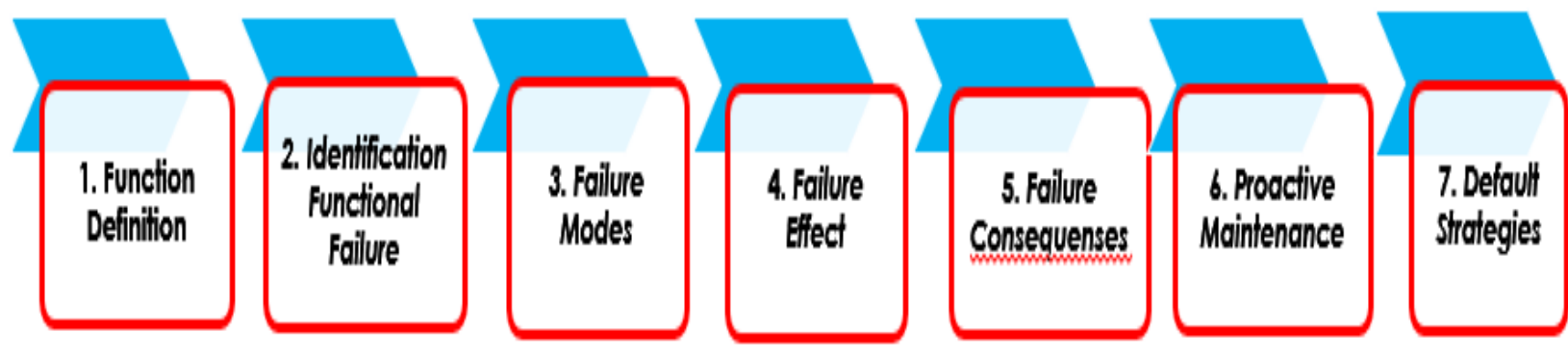

Figure 1. Steps for implementing RCM

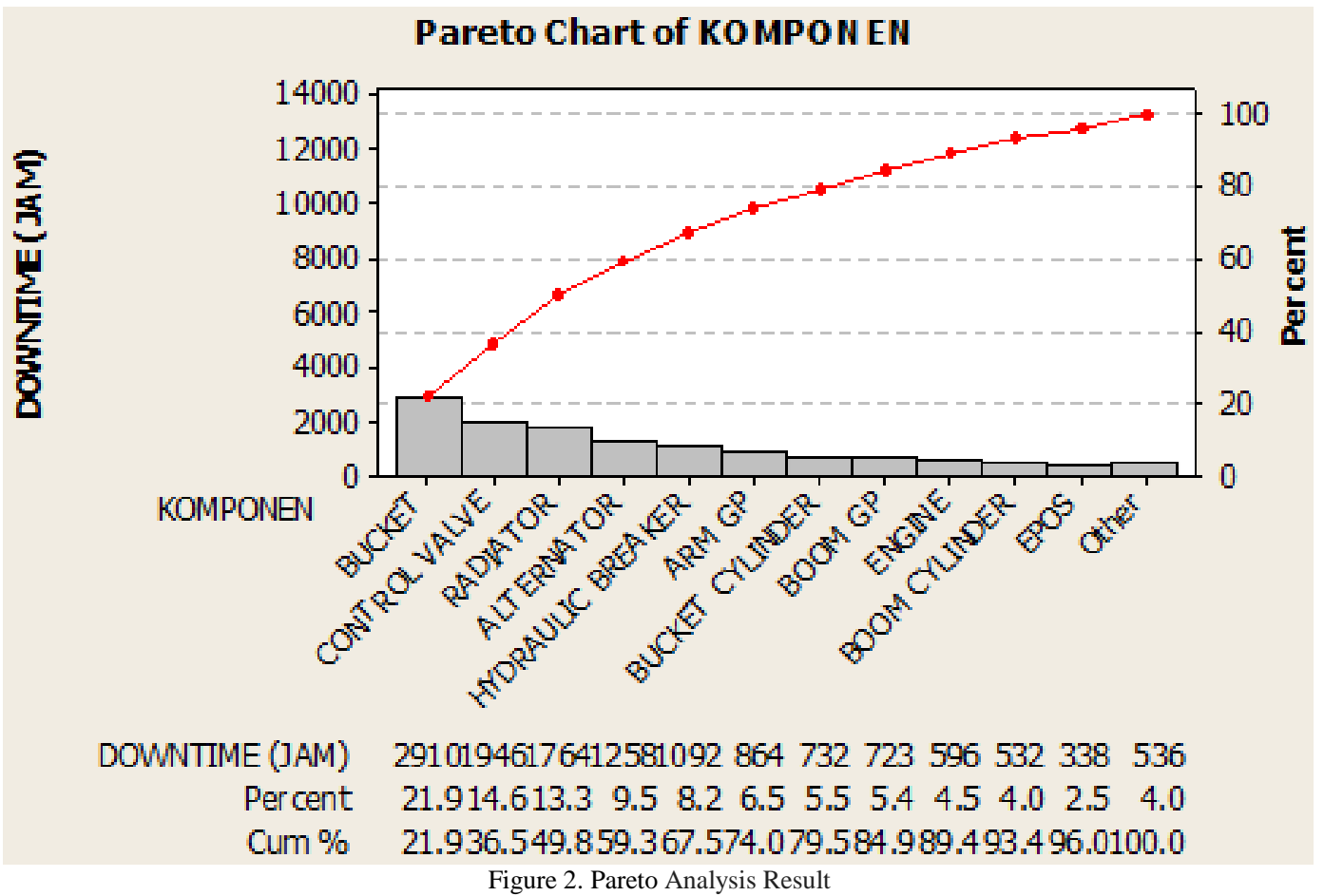

Furthermore, FMEA analysis is implemented to be able to find out the functions of critical components, malfunction, causes of failure and the consequences of failure. The last analysis is to do Reliability Centered
Maintenance (RCM) analysis with the following steps (see Figure 1)

From the implementation of RCM analysis, the right maintenance strategy will be obtained so that the excavator 
unit downtime can be minimized and the production of excavators can increase.

\section{RESULTS AND DISCUSSION}

A. Downtime and Determination Critical Components of the S500-LCV Excavator

The results of the S500-LCV excavator downtime data analysis at PT X in 2016 until the beginning of 2018 can be seen on Table 1. Downtime data is presented with values above 250 hours to make it easier to present data.

TABLE 1 .

S500-LCV EXCAVATOR DOWNTIME DATA FOR 2016 - EARLY 2018

\begin{tabular}{cccc}
\hline \hline Component & Downtime (hour) & Component & Downtime (hour) \\
\hline Boom GP & 723.0 & Track Roller & 272.0 \\
Engine & 596.0 & Bucket Cylinder & 732.0 \\
Alternator & 1258.0 & Epos & 338.0 \\
Bucket & 2909.5 & Arm GP & 864.0 \\
Control Valve & 1946.0 & Hydraulic Breaker & 1092.0 \\
Radiator & 1764.0 & Boom Cylinder & 532.0 \\
\hline \hline
\end{tabular}

Based on the Table 2, then pareto analysis is implemented by using minitab 16 software. The results can be seen on the Figure 2. From Figure 2, five critical components are determined, then the critical component is further analyzed.

From the results of the Pareto analysis, the critical components obtained are bucket, control valve, radiator, alternator and hydraulic breaker because the components are included in the category of the five largest components. The component is then analyzed for maintenance costs, loss production costs.

\section{B. Maintenance Cost and Loss Production Cost of the S500-LCV Excavator at PT X}

Maintenance costs are costs that arise due to maintenance activities on a unit. The amount of maintenance costs is influenced by the length time of the maintenance or repair, labor costs, costs due to repairs and the purchase price of the replaced components. The amount of each variable is determined based on the provisions of PT X and the value of prices from the vendor directly. The cost of loss production with maintenance costs with the type of preventive maintenance can be seen on the Table 3 and corrective maintenance can be seen on the Table 4 .

\section{Reliability Centered Maintenance}

Evaluation using the RCM worksheet outlined some information, consequences and determination of the improvements that must be made. This study used the RCM worksheet in accordance with the book by [6] entitled Reliability Centered Maintenance II. The worksheet is suitable, easy to understand and also suitable to be applied so that hopefully, later the right maintenance strategy decision will be obtained. The results of the RCM analysis in this study can be seen on the Table 5 .

TABLE 3.

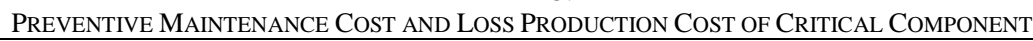

\begin{tabular}{ccccccc}
\hline \hline No & Component & Repair (hour) & Labor Cost (Rp) & Loss Production (Rp) & Parts (Rp) & Total Cost (Rp) \\
\hline 1 & Bucket & 8 & 60,000 & $4,571,250$ & $4,700,000$ & $41,750,000$ \\
2 & Control Valve & 56 & 60,000 & $4,571,250$ & $2,796,485$ & $262,146,485$ \\
3 & Radiator & 24 & 60,000 & $4,571,250$ & $3,500,000$ & $114,650,000$ \\
4 & Alternator & 8 & 60,000 & $4,571,250$ & $7,178,086$ & $44,228,086$ \\
5 & Hydraulic Breaker & 24 & 60,000 & $4,571,250$ & $7,500,000$ & $118,650,000$ \\
\hline \hline
\end{tabular}

TABLE 4.

Corrective Maintenance Cost and Loss Production Cost of CRITICAL Component

\begin{tabular}{clccccc}
\hline \hline No & Component & Repair (hour) & Labor Cost (Rp) & Loss Production (Rp) & Parts (Rp) & Total Cost (Rp) \\
\hline 1 & Bucket & 56 & 60,000 & $4,571,250$ & $18,087,955$ & $277,437,955$ \\
2 & Control Valve & 56 & 60,000 & $4,571,250$ & $2,796,485$ \\
3 & Radiator & 16 & 60,000 & $4,571,250$ & $33,218,780$ & $107,318,780$ \\
4 & Alternator & 8 & 60,000 & $4,571,250$ & $7,178,086$ & $44,228,086$ \\
5 & Hydraulic Breaker & 40 & 60,000 & $4,571,250$ & $265,000,000$ \\
\hline \hline
\end{tabular}


IPTEK Journal of Proceedings Series No. (5) (2019), ISSN (2354-6026)

The $1^{\text {st }}$ International Conference on Business and Management of Technology (IConBMT)

August 3rd 2019, Institut Teknologi Sepuluh Nopember, Surabaya, Indonesia

TABLE 5 .

RCM DECISION WORKSHEET EXCAVATOR S500-LCV

\section{RCM DECISION WORKSHEET}

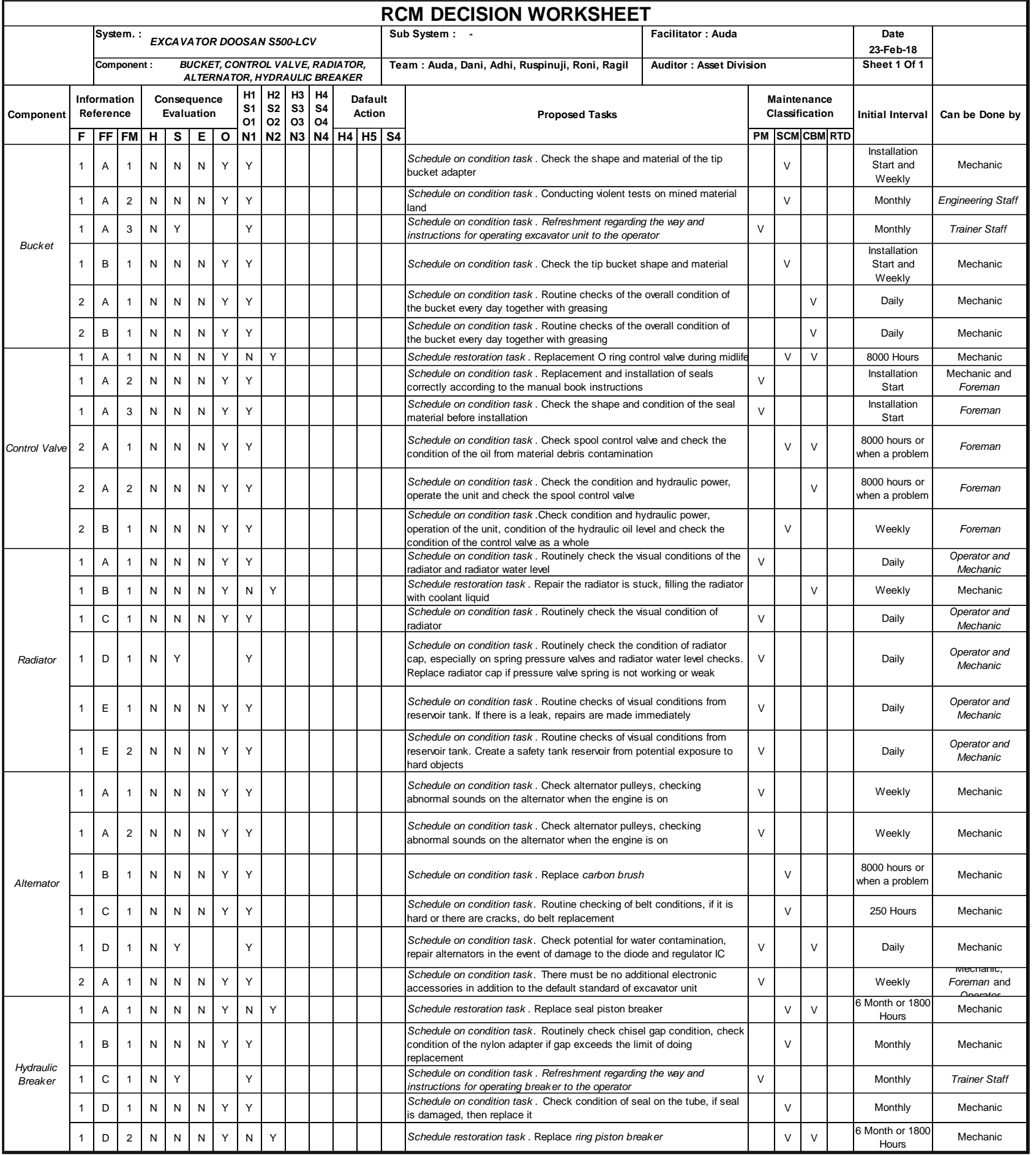

\section{CONCLUSIONS}

The result of implementing RCM are as follow that PT $\mathrm{X}$ previously implemented the S500-LCV excavator maintenance system with a type of schedule and corrective maintenance, from the results of the research the proposed types of maintenance are preventive maintenance, corrective maintenance and a combination between both maintenance for some excavator critical components.

The critical component of the S500-LCV excavator at PT X is determined by a pareto analysis that considered the 
The $1^{\text {st }}$ International Conference on Business and Management of Technology (IConBMT)

August 3rd 2019, Institut Teknologi Sepuluh Nopember, Surabaya, Indonesia

value of downtime that occurs. Five critical components along with the value of downtime determined based on the results of the analysis are bucket (2909.5 hours), control valve (1946 hours), radiator (1764 hours), alternator (1258 hours) and hydraulic breaker (1092 hours).

The maintenance costs of each critical component with the type of preventive maintenance are bucket (Rp. 41,750,000.00), control valve (Rp. 26,146,485.00), radiator (Rp. 114,650,000.00), alternator (Rp. 44,228,086.00) and hydraulic breakers (Rp. 118,650,000.00). For the type of corrective maintenance: bucket (Rp. 277,437,955.00), control valve (Rp. 26,146,485.00), radiator (Rp. 107,318,780.00), alternator (Rp. 44,228,086.00) and hydraulic breaker (Rp. 450,250,000.00).

The proposed type of maintenance based on the RCM decision worksheet by considering the maintenance costs are bucket (preventive maintenance), control valve (preventive maintenance), radiator (preventive maintenance because it considers safety and operations but there will be an additional cost of $\mathrm{Rp}$. 7,331,220.00), alternator (preventive maintenance) and hydraulic breakers (preventive maintenance).

\section{ACKNOWLEDGMENT}

I am very thankful to all employees and management of the company because they have been given time and opportunity to do research. Thank you also the author said because the company has facilitated everything, so the author can complete the research

\section{REFERENCE}

[1] R. Rochmanhadi, Alat Berat dan Penggunaannya. Jakarta: YBPPU, 1992.

[2] M. R. A. Simanjuntak and F. Ferrari, "Peran excavator terhadap kinerja proyek konstruksi rumah tinggal di Jakarta Selatan," $J$. Ilm. MEDIA Eng., vol. 3, no. 1, 2013.

[3] D. N. Blischke, Case Studies in Reliability and Maintenance. Canada: John Wiley \& Sons, Inc., 2003.

[4] E. Zio, An Introduction to the Basics of Reliability and Risk Analysis. Singapore: World Scientific, 2007.

[5] N. Regan, The RCM Solution: Reliability-centered Maintenance. New York: Industrial Press, 2012.

[6] J. Mourbay, "Reliability Centered Maintenance II, Second Edition.” Industrial Press Inc., New York, 1997. 